\title{
SULFATE AND CHLORIDE RESISTANCE PROPERTIES OF PORTLAND CEMENT BLENDS
}

\author{
Abu Zakir Morshed*1, Suraiya Hashi ${ }^{2}$, Nitai Biswas ${ }^{3}$ And Miftaul Sadik ${ }^{4}$ \\ ${ }^{1}$ Dept. of Civil Engineering, KUET, Bangladesh \\ ${ }^{2}$ Dept. of Civil Engineering, BAUET, Natore, Bangladesh \\ ${ }^{3}$ Assistant Engineer, Leisure Bangladesh Ltd., Bangladesh \\ ${ }^{4}$ Production \& Quality Control Engineer, Crown Cement Concrete and Building, Bangladesh
}

Received: 07 May $2019 \quad$ Accepted: 24 March 2021

\begin{abstract}
About 53\% area of Bangladesh is alluvial deposited and affected by sulfate, salinity and chloride in water and soil. Existing sulfate and chloride can severely damage the building in coastal regions. In this paper durability of cement is evaluated on the basis of strength of mortar cube, concrete cylinder test. Besides the sulfate resistance is measured by change of length of the mortar bar specimens during exposure to sulfate solution and the attacking chloride properties by Rapid chloride ion penetration test using OPC, PCC, 20\% FA, 30\% FA and 40\% FA. The strength was observed in cube sample about 40.65, 37.2MPa after 13 weeks in sulfate solution and linear expansion was obtained about $0.28 \%$ and $0.133 \%$ for OPC and PCC cement with reference to the water. The compressive strength of the cylindrical specimens was about 16.96, $18.34 \mathrm{MPa}$ for OPC and PCC, respectively at the age of 28 days. The permeability of chloride ion of OPC sample was $22.8 \%$ higher than the PCC at this age.
\end{abstract}

Keywords: Blended cement; Length change; Sulfate attack; RCPT.

\section{INTRODUCTION}

Durability of concrete is a key factor in the longevity of concrete structures. The durability is a parameter that can endure the weather action, chemical attack, abrasion, or any kind of deterioration during its anticipated service year (ACI, 2017). For the aggressiveness of the environment, the abrasion, weather actions, and chemical attack affect the durability of concrete by the alternate process of drying and wetting in coastal regions. Chemicals like sulfate and chloride in soil and water react with cement paste and form some unwanted but insidious compounds that gradually precludes the development of the compressive strength of concrete. Thus, cause the lack of durability that imparts premature cracking in concrete, corrosion of reinforcement within some short periods of construction (Bosunia et al., 2002).

Sulfate attack is a well-known deterioration for concrete in coastal regions. In Bangladesh, the amount of sulfate in both soil and water is remarkably high. The water used during a concrete mix, curing contains a high amount of sulfate.

Deterioration of concrete by sulfate attack is known to take two forms that are distinctly different from each other (Monteiro, 2006). The main form in which sulfate attack manifests itself is expansion. When concrete is in contact with sulfate subsuming water, an external sulfate attack leads to the formation of massive gypsum and ettringite. The supplant sulfate propagated the reaction towards the concrete core resulting in an internal sulfate attack (Breysse, 2010). These reactions highly involve the cement paste, rather than aggregates but the aggregate contains sulfate minerals cause an internal attack. However, sulfate attack can result in progressive loss of strength and loss of mass, which happens when the cohesiveness of the cement hydration product is denigrated. The thaumasite form of sulfate attack is an example of mass loss and disintegration of concrete (Ramezanianpour et al., 2012). A study by Taryal et al. (1986) reports that for hot and dry weather, curing for 14 days by sprinkling water twice a day and keeping the concrete covered by plastic sheets is a very effective method for graining the required strength. The presence of a high amount of sulfate and chloride in soil or water may reduce the design life of structures. Sulfate attack, salt crystallization, and Chloride attack are more severe in coastal areas in Bangladesh.

Supplementary cementitious materials (SCM) like fly ashes, slag cement, and silica fume act as a resisting agent of sulfate attack in hardened concrete (Prakash Joshi et al., 2002). These materials added to make concrete mixtures more economical, reduce permeability, increase strength, or influence other concrete properties. Portland Composite Cement performs better than Ordinary Portland cement in case of resisting chemical attack due to the presence of SCM components. 
Depending on the properties of SCM components this study attempts to study the sulfate and chloride attack risk of marine structures by mixing the cement with different ratios of fly ash $(20 \%, 30 \%$, and $40 \%)$ with a designed concrete mixture ratio. The strength is studied by observing the concrete cylinder and mortar cube and length change is recorded by bar specimens using a length comparator. In addition, Chloride attack is assessed by the Rapid Chloride Permeability Test (RCPT) test replacing the Ordinary Portland Cement (OPC) by fly ash after curing normal water and $\mathrm{Na} 2 \mathrm{SO} 4$ water in different time such as 1, 2, 3, and 4 weeks.

For the necessity of high chloride and sulfate resistance concrete for long durability in Bangladesh, it is important to deliver a new idea on how to improve the strength and durability of concrete even in sulfate and chloride containing water or soil. So that structure can withstand a good performance, as well as the cost of repairing, can be bound down.

\section{METHODOLOGY}

Concrete strength plays a significant role in defining the durability of structures. Concrete is an amalgam of the aggregate of both fine and coarse with a sufficient amount of cement as well as water. This study carried out to study the properties of mortar (a mixture of cement with sand particle) to observe how it changes properties in sulfate and chloride exposure by creating an artificial coastal region in the laboratory. For a better comparison, we choose the Portland Composite Cement (PCC) and Ordinary Portland Cement (OPC) as the cement materials substituting it to fly ash by weight $(20 \%, 30 \%$, and $40 \%)$.

\subsection{Materials}

As for the mortar sample, cement was collected from local suppliers of the different commercial brands for both OPC and PCC. The $20 \%, 30 \%$, and $40 \%$ fly ash replacements to cement then carried out in the laboratory by manually. Cement particles were substituted by flyash by their weight. Sylhet sand was used in this study as fine aggregate. The chemical composition of the materials obtained from X-ray Flouroscence (XRF) analysis are narrowed down in Table 1.

Table 1: Chemical composition of cementitious materials

\begin{tabular}{ccc}
\hline Com-pounds & $\begin{array}{c}\text { PCC } \\
\text { Concentration } \\
\text { Unit, \% }\end{array}$ & $\begin{array}{c}\text { OPC } \\
\text { Concentration } \\
\text { Unit, \% }\end{array}$ \\
\hline $\mathrm{SiO}_{2}$ & 26.735 & 21.27 \\
$\mathrm{Al}_{2} \mathrm{O}_{3}$ & 13.635 & 5.34 \\
$\mathrm{Fe}_{2} \mathrm{O}_{3}$ & 3.5 & 2.28 \\
$\mathrm{CaO}$ & 53.489 & 63.92 \\
$\mathrm{MgO}$ & 2.552 & 3.91 \\
$\mathrm{SO}$ & 1.744 & 2.32 \\
$\mathrm{Na}_{2} \mathrm{O}$ & 0.123 & 0.47 \\
$\mathrm{~K}_{2} \mathrm{O}$ & 0.907 & - \\
$\mathrm{TiO}_{2}$ & 0.915 & - \\
$\mathrm{P}_{2} \mathrm{O}_{5}$ & 0.058 & - \\
$\mathrm{MnO}$ & 0.221 & - \\
\hline
\end{tabular}

Table 2: Concrete mixutre proportion

\begin{tabular}{llcccc}
\hline $\begin{array}{l}\text { Batch } \\
\text { No. }\end{array}$ & Sample type & Cement & $\begin{array}{c}\text { Fine } \\
\text { aggregate }\end{array}$ & $\begin{array}{c}\text { Coarse } \\
\text { aggregate }\end{array}$ & $\begin{array}{c}\text { Fly Ash } \\
\text { (FA) }\end{array}$ \\
\cline { 3 - 6 } & & $\mathrm{kg}$ & $\mathrm{kg}$ & $\mathrm{kg}$ & $\mathrm{kg}$ \\
\hline 1 & OPC & 5.7 & 12.6 & 20 & - \\
2 & PCC & 5.7 & 12.6 & 20 & - \\
3 & $20 \%$ FA & 4.56 & 12.6 & 20 & 1.14 \\
4 & $30 \%$ FA & 4.00 & 12.6 & 20 & 1.71 \\
5 & $40 \%$ FA & 3.42 & 12.6 & 20 & 2.28 \\
\hline
\end{tabular}




\subsection{Concrete Mix Design}

For casting the mortar cube and bar specimens, a water-cement ratio of 0.485 was chosen for the execution of OPC and PCC with $20 \%, 30 \%$, and $40 \%$ fly ash replacements. The mixture of 1 part of cement with 2.75 parts of sand by weight was followed for all the mortar specimens (ASTM C 109, 2008).

For the cylindrical specimens, a concrete mix was well designed on basis of the weight of the materials. The concrete cylinders were cast by following 1:2.2:3.5 mix ratio using water-cement ratio 0.6 . For casting $20 \%$ FA, $30 \%$ FA, $40 \%$ FA sample the OPC and PCC types of cements were replaced by fly ash. Table 2 shows the mix proportion of the prepared samples.

\section{PREPARATION AND TEST OF CEMENT MORTAR SPECIMENS}

\subsection{Strength parameter}

Following ASTM C 109 standards, two groups of cube specimens were prepared for testing the compressive strength parameter. Each group contained 21 nos. of cube specimens (2"x2"x2") of a total of 126 nos. Water curing carried out for the samples initially up to achieving $20 \mathrm{MPa}$ strength. After achieving $20 \mathrm{MPa}$ strength, one group of the samples were immersed in sulfate $\left(5 \% \mathrm{Na}_{2} \mathrm{SO}_{4}\right)$ solution by covering the curing tank with a plate or tape. The sulfate solution made by an accumulation of $50 \mathrm{~g} \mathrm{Na}_{2} \mathrm{SO}_{4}$ in $900 \mathrm{~mL}$ water and adulterated with additional distill water to obtain 1 liter of solution. The mixing temperature of the solution maintained within $23^{\circ} \mathrm{C} \pm 2{ }^{\circ} \mathrm{C}$ and made sure that the $\mathrm{pH}$ range of the mixture lies between 6.0 to 8.0. Necessary precautions should be taken to keep the container sealed so that no air can entrain into it. The mixing procedure should be prepared before the day of immersion and kept it $24 \mathrm{hrs}$ under observation for ensuring the $\mathrm{pH}$ of the solution. Counting the day form the starting of sulfate immersion of the specimens, compressive strength test of the mortar cube specimens were executed for 1,2,3,4,8, and 13 consecutive weeks for studying the initial and final ages.

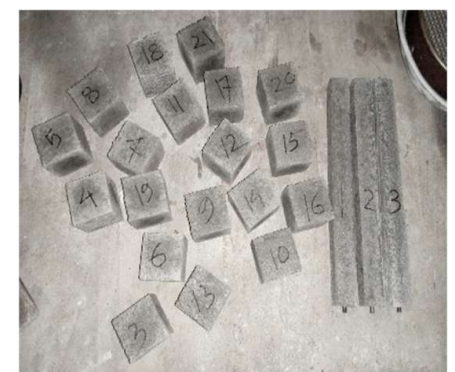

Figure 1: Preparation of mortar specimens

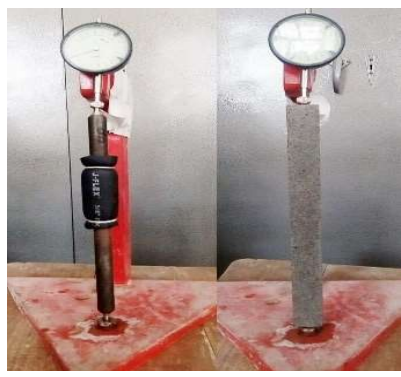

Figure 2: Length measure-ment of bar specimen

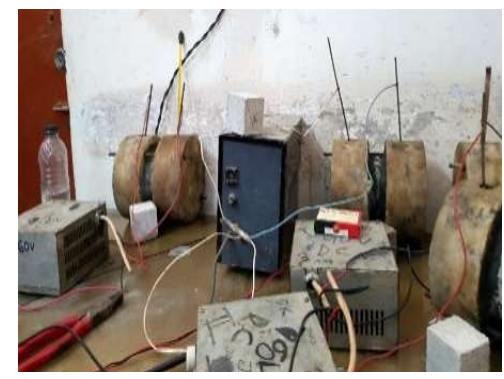

Figure 3: RCPT test setup of cylindrical specimen

\section{2 length Change Parameter}

For measuring the length changes of the mortar specimens, ASTM C157 / C157M - 17 procedures were followed where $250 \pm 2.5 \mathrm{~mm}$ bar specimens were cast for different types of cement and $20 \%, 30 \%$, and $40 \%$ fly ash replacements. Each set of mortar bar scontains a total of six numbers of bar and length was supervised by a length comparator device. In this deice, the distances between the bolts with the formwork were $250 \pm 2.5 \mathrm{~mm}$, the length inside the specimen is $7.5 \pm 0.5 \mathrm{~mm}$ and outside the specimen is $5 \mathrm{~mm}$. The base of the comparator into which gage stud on the lower end of the bar fits was cleaned. After that sample was placed vertically between the two stud at top and bottom. The data of each sample length was then recorded for the two group of specimen with a precision of \pm 0.001 . At the measurements, great care were taken to calibrate dial indicator and to clean the grooves in which the specimens were put.

\subsection{Preparation and Test of Concrete Cylindrical specimens}

\subsubsection{Strength parameter}

OPC, PCC, 20\%, 30\%, 40\% Fly Ash (FA) cylinders of diameter $100 \mathrm{~mm}$ (4 in) x height $200 \mathrm{~mm}$ (8 in) were made by five batch following ASTM C192/ C192M procedure. A total of 12 cylindrical specimens completed for each mix proportion. After preparing, the cylindrical specimens put into for submersion in both normal water and $\mathrm{Na}_{2} \mathrm{SO}_{4}$ water. A total of 60 specimens of 4 in $x 8$ in the cylindrical sample kept ready for the compressive strength test. 


\subsubsection{Chloride ion penetration test}

The Rapid chloride ion penetration test was carried out according to ASTM C 1202 by an RCPT tester. There are four chambers in the RCPT tester and at a time four concrete samples can be tested. At the starting of the test, 60 Volt DC is automatically selected by the instrument. One lead is immersed in a $3.0 \%$ salt $(\mathrm{NaCl})$ solution and the other in a $0.3 \mathrm{M}$ sodium hydroxide $(\mathrm{NaOH})$ solution (ASTM 1202). Actual voltage, current, and temperature shows during the study. The penetration was measured in terms of the total passing charge in Columbus through a slice of the cylinder in 6 hrs. For carrying out this test, $\varnothing 4$ in. $x 6$ in. of cylindrical specimens prepared using the mixed ratio of concrete for each batch of cement. For the necessary experimental setup, all the specimens resized at $\varnothing 4 \mathrm{in}$. $\mathrm{x} 2 \mathrm{in}$ which were cured before in $\mathrm{Na}_{2} \mathrm{SO}_{4}$ solution. The setup required an arrangement of \#100 sieve with a set of voltage supply and multi-meter for measuring current and voltmeter with a sufficient amount of cable as well as M-seal. The amount of current and voltage was recorded by Multi-meter and the solution temperature was recorded with a thermometer.

\section{RESULTS AND DISCUSSIONS}

\subsection{Development of Compressive Strength of Mortar Cube}

The following Table 3 shows the development of the compressive strength of the cement mortar cube in exposure time in sulfate solution up to the age of 13 weeks.

The initial strength of OPC, PCC, 20\% FA, 30\% FA, 40\% FA in water were shown about 22.45, 19.47, 21.57, $21.90,8.43 \mathrm{MPa}$, respectively and sulfate strengths about 21.25, 17.93, 19.73, 21.90, $7.93 \mathrm{MPa}$, respectively. At an early age, up to 4 weeks of strength in water solution was higher than the strength in a sulfate solution. At the age of 4 weeks (28 days), the maximum strength in sulfate solution was $30 \% \mathrm{FA}$ about $25.90 \mathrm{MPa}$, and $40 \% \mathrm{FA}$ showed the lowest strength was about $11.83 \mathrm{MPa}$. According to ASTM standards 28 days minimum strength needs to be $25 \mathrm{MPa}$. From the table below the compressive strength of both, water and sulfate solution was greater than the strengths of the standard at 4 weeks ages except the $40 \%$ FA samples. It is obvious that $40 \%$ FA replacement causes a drastic decrease in the development of compressive strength of concrete from the initial stage.

Table 3: Development of Compressive strength of mortar cube

\begin{tabular}{lllllll}
\hline \multirow{2}{*}{$\begin{array}{l}\text { Mixture } \\
\text { designation }\end{array}$} & 1 week & 2 weeks & 3 weeks & 4 weeks & 8 weeks & 13 weeks \\
\cline { 2 - 6 } OPC & 21.25 & 24.95 & 26.25 & 28.50 & 35.00 & 35.55 \\
PCC & 17.93 & 21.43 & 24.43 & 23.97 & 26.63 & 31.17 \\
$20 \%$ FA & 19.73 & 23.53 & 24.63 & 25.77 & 28.43 & 33.10 \\
$30 \%$ FA & 21.20 & 23.10 & 24.77 & 25.90 & 28.53 & 37.80 \\
$40 \%$ FA & 7.93 & 9.47 & 11.53 & 11.83 & 12.47 & 15.63 \\
\hline
\end{tabular}

After 4 weeks the $30 \%$ FA sample gains $90.88 \%$ of OPC and $8.05 \%, 0.50 \%$ higher than PCC and $20 \%$ FA specimens' strength in sulfate solution. At the later age (13 weeks) the $30 \%$ FA specimen showing about 37.80 $\mathrm{MPa}$ that is the higher development of gaining strengths that OPC as well as other specimens. It can be concluded that concrete can perform better with $30 \%$ fly ash replacements of ordinary Portland cement.

\subsection{Development of Compressive strength of Concrete}

The following plot represents the relationship between the compressive strength of the concrete cylinder and the immersion time in the sulfate solution. The time scale was a plot in weeks. The results showed that the compressive strength of the concrete increased when Fly Ash used in concrete by replacement of OPC. But at a time the compressive strength became decreased by using a high percentage of Fly Ash.

From the observed data the compressive strength of specimens shows variation with the type of curing as well as curing medium. The sulfate curing fulfilled in completely sealed condition avoiding the evaporation of the solution. The curing of the cylinders in normal water gives higher compressive strength than in sulfate solution specimens by 5\%-15\% at early age. After the 4 weeks, the strength starting to drop by around $1.5 \%-7 \%$ maximum for the different types of concrete mixed.

For OPC cylinder specimens, it is observed that the compressive strength decreased about $6.81 \%$ for sulfate curing after 4 weeks. Unlike OPC, the PCC shows a consistence result of the compressive strength with a slight decrease 
about $1.74 \%$ and $2.54 \%$ after 1 and 4 weeks. On the other hand, $20 \%$ FA sample shows a better performance in sulfate solution than other specimens. Though 30\% FA showing better strength for cube specimens but here for compressive strength for cylinder specimens, it decreases more drastic than $20 \%$ FA specimens. At the early age, the strength reduction is about $12.33 \%$ that is second last deduction among all the specimens. As for later age (4 weeks), about $5.93 \%$ strength reduction recorded. Studying all the data, it can be narrowed down to that $20 \%$ FA shows a better strength profile in exposure of a sulfate solution.

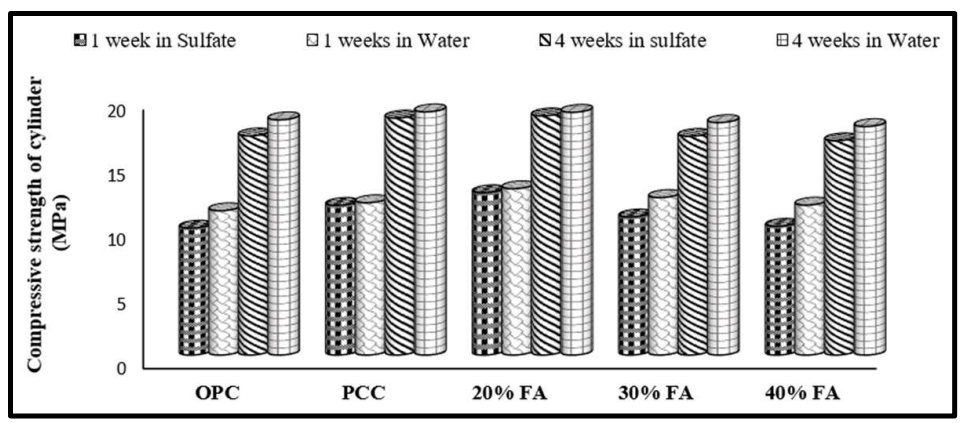

Figure 4: Comparison of compressive strength of concrete cylinder

After immediate exposure to a $\mathrm{Na}_{2} \mathrm{SO}_{4}$ solution, sulfate can intrude more and replace the pore space of concrete with sulfate ion. As time passes, the intruded sulfate started to affect the concrete internally. Due to the external and internal sulfate attack in concrete, the formation of ettringite takes place at the particle interface and fills up the air voids. Thus, it affects the concrete strength as a formation of a crystal layer in the aggregate cement interface. And for using a higher percentage of fly ash, the compressive strength decreased severely because of the extensive amount of fly ash that leads to a weak bond between the cement paste and the aggregate.

\subsection{Resistance of Sulfate attack}

The following graph at figure 5 shows the plotting of the changes of length of specimens with respective time. From the graph, it is obvious that the highest change of the length of the mortar bars specimens of OPC is $0.078 \%$ and the lowest length change was PCC a $40 \%$ FA was about $0.013 \%$ at 8 weeks.

The expansion rate at a later age become stable. The expansion after 8 weeks in a sulfate solution of OPC, PCC and $30 \%$ FA sample was $0.280 \%, 0.032 \%$, and $0.166 \%$. The lowest length change of the mortar bars of PCC specimens is $0.001 \%$ at 8 weeks. In water, the length change of the mortar bar is lower than the length change of the mortar bar in the sulfate solution.

After 8 weeks the expansion of the mortar bar became stable for PCC, 20\% FA, and 30\% FA compared to initials. Because in sulfate solution, ettringite is produced and as a result, cube specimens are expanded and its length change is increased with respect to time.

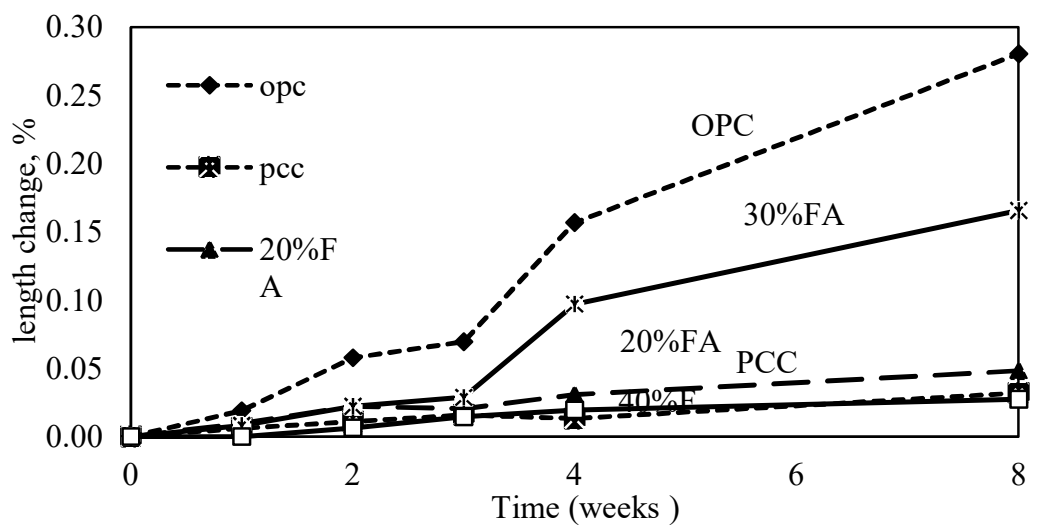

Figure 5: Comparison of length change with sulfate immersed time

The expansion rate in both water and sulfate was rapid because of the water absorption rate at early age. It increases due to the dry concrete was immersed in curing. When the sample immersed in a sulfate solution, the sulfate replaced by a water molecule. After time passes the generated pore space between mortars filled with the sulfate molecule. The size of the sulfate particle is larger than the water molecule, the expansion rate was initially high. At a time, when pore space will be filled and hydration took placed, the amount of water or sulfate molecule 
decreases from initials. As a result, the consumption of sulfate molecules seems steady and the specimen's gains a stable slope of expansions.

\subsection{Resistance to Chloride Ion Penetration}

The chloride ion penetration test completed on the basis of total charge (expressed as coulomb) passing through a slice of a concrete cylinder in 6 hours at the age of 1,2, 4, 8 weeks. The relationship between the amount of passing charge through the concrete cylinder and time is represented in the following Figure 6 . The passing amount of charge through OPC, PCC, $20 \%$ FA, 30\% FA \& 40\% FA was measured. The passing charge was generally very high for a low percentage Fly ash sample at the age of one week. The high charge passed 5070 coulombs in the OPC sample at a single week.

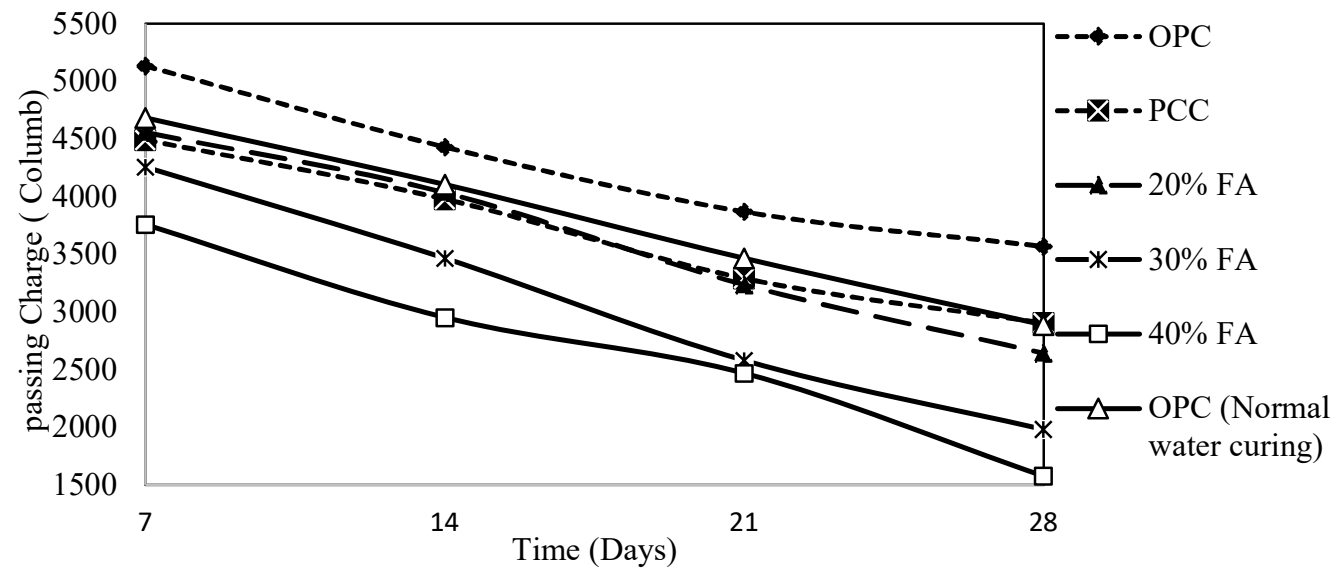

Figure 6: Comparison of chloride ion penetration with sulfate immersed time

After 2 weeks the highest passing charge was recorded for OPC was still in high range. At the age of $3 \& 4$ weeks, the passing charge through OPC sample was still higher than other samples. In normal water curing, the OPC sample showed lower charge than OPC sample curing by $\mathrm{Na}_{2} \mathrm{SO}_{4}$ water. The amount of charge in coulomb at 1 , 2,3 \& 4 weeks of OPC sample (curing in $\mathrm{Na}_{2} \mathrm{SO}_{4}$ water) is $5133 \mathrm{C}, 4430 \mathrm{C}, 3868 \mathrm{C} \& 3567 \mathrm{C}$, respectively. And 4682 C, 4105 C, 3512 C, \& 2887 C for normal water curing sample at the ages of 1, 2, 3 \& 4 weeks, respectively. Because the fly ash with blended cement reduce the pore of the concrete that resist more chloride ion passing through the concrete.

The amount of current passing through the samples shows the number of ions not only chloride but all ions in the pore solution. From various researches, it is concluded that the supplementary cementitious materials (fly ash) or chemical admixtures can mislead the results due to the chemical composition of the pore solution than its actual permeability. As a result, some researchers do not recommend the RCPT to evaluate the chloride permeability of concrete containing these materials. As a result, some researchers do not recommend the RCPT to evaluate the chloride permeability of concrete containing these materials (Shi et al., 1998).

\section{CONCLUSION}

This study was carried out in three parts. Firstly, measurement of the compressive strength by $2 \times 2 \times 2$ in. mortar cube specimens as well as $\Phi 4$ in $x 8$ in concrete cylindrical specimens. Secondly, measurement of the length change of $250 \pm 2.5 \mathrm{~mm}$ cement mortar. Finally, chloride ion penetration test of the cylindrical specimens. All the sample casing was carried by same amount of mix proportion with different type of cement. The fly ash was replaced by the same amount of cement by weight. From this study, it can be concluded that the $30 \%$ FA sample shows the greater strength after 13 weeks and 20\% FA was following to 30\% FA. The length change of $30 \%$ FA was largest compared to other composition of FA but $20 \%$ FA performs better in this parameter. Looking at the strength of $30 \%$ FA after 13 weeks the sample shows a higher expansion rate is reasonable. After long time the strength is developing and length change is dropping. Studying the concrete cylindrical specimen the PCC, OPC and 30\% FA gives almost same amount of strength with a great variety of length change. The Chloride ion permeability of $30 \%$ FA is low in the scale ASTM standard category. So Instead of OPC and PCC we can use $30 \%$ FA cement by replacing 30\% cement by Fly ash for reducing environmental effect by using wastage. 


\section{REFERENCES}

ACI. (2017). ACI Concrete Terminology - An ACI Standard. Retrieved from American concrete Institute: https://www.concrete.org/topicsinconcrete/topicdetail/durability $\% 20 \mathrm{of} \% 20$ concrete? search=durability $\%$ 20 of $\% 20$ concrete

ASTM. (2008). ASTM C 109/C 109M - 07, Standard Test Method for Compressive Strength of Hydraulic Cement Mortars. ASTM International.

ASTM C 1202 Standard Test Method for Electrical Indication of Concrete's Ability to Resist Chloride Ion Penetration. (2019). In Annual Book of ASTM standards (pp. 639-644). United States: ASTM.

ASTM, i. (2017). ASTM C157 / C157M - Standard Test Method for Length Change of Hardened HydraulicCement Mortar and Concrete. United States: ASTM.

ASTM, I. (2020). ASTM C 109 -Standard Test Method for Compressive Strength of Hydraulic Cement Mortars. United States: ASTM International.

ASTM, I. (2019.). ASTM C192 / C192M - 19-Standard Practice for Making and Curing Concrete Test Specimens in the Laboratory. United States: ASTM International.

C. Shi, J. S. (1998). Effect of Supplementary Cementing Materials on the Specific Conductivity of Pore Solution and Its Implications on the Rapid Chloride Permeability Test Results. Transportation Research Board (TRB), 389-394.

D. Breysse (2010). Deterioration processes in reinforced concrete: an overview. Science Direct, 28-56. doi:https://doi.org/10.1533/9781845699536.1.28

M S Z Bosunia, J. R. (2002). Improving the performance of the concrete in coastal areas of Bangladesh. ICE, 287-296.

Monteiro, J. M. Paulo (2006). Scaling and saturation laws for the expansion of concrete exposed to sulfate attack. PNAS, 11467-11472.

Ramezanianpour, Amir. Mohammad. (2012). Sulfate Resistance and Properties of Portland-limestone Cements. TSpace.

Shamim Z. Bosunia, J.R. Choudhury (2001). Durability of concerete in coastal area of Bangladesh.

Taryal, Dr. M. K.Chowdhury, SeppoMatala (1986). The effect of practical curing methods used in Saudi Arabia on compressive strength of plain concrete. Elsevier, 633-645. doi: https://doi.org/10.1016/00088846(86)90036-0

(C) 2021 the Authors. Journal of Engineering Science published by Faculty of Civil Engineering, Khulna University of Engineering \& Technology. This is an open access article under the terms of the Creative Commons Attribution-NonCommercial-NoDerivatives License, Which permits use and distribution in any medium, provided the original work is properly cited, the use is non-commercial and no Modifications or adaptations are made. 